\title{
Complex and Commission Expertise on Illegal Actions in the Public Sector
}

\author{
Zvyagin S.A.* \\ Department of Civil-Legal and Economic Disciplines \\ Voronezh Institute of the Ministry of Internal Affairs of \\ Russia \\ Voronezh, Russia \\ e-mail:Patzv@mail.ru
}

Strygina I.E.

Department of Civil-Legal and Economic Disciplines Voronezh Institute of the Ministry of Internal Affairs of Russia

Voronezh, Russia

e-mail: Strygina.in@yamdex.ru

\begin{abstract}
The paper considers certain organizational and methodological aspects of the production of complex and commission accounting examinations on illegal economic actions in the budget sphere. The authors' methodology for the work of an expert accountant in organizing and conducting complex and commission accounting examinations is proposed.
\end{abstract}

Keywords - accounting expertise, distortion of accounting (financial) statements, counteraction to economic violations in the budget sphere, methods for detecting distortions in accounting data, organizational and methodological features of commission examinations.

\section{INTRODUCTION}

In the modern world the investigation of illegal economic activities in the public sector is not complete without the use of expert knowledge. The use of such knowledge by several experts in the same field or the knowledge of experts of various specialties leads to the need for commission or complex examinations. The relevance of conducting complex and commission examinations on illegal economic actions in the public sector, in our opinion, is obvious, as evidenced by the expert practice of conducting examinations in the public sector [1].

The increase in the number of complex and commission examinations in the public sector, in our opinion, is dictated by:

- the quantitative and qualitative growth of illegal actions in the public sector;

- the expenditure of the list of issues to be addressed by accounting expertise;

- the use of modern information technologies in ensuring the accounting process and the implementation of illegal actions in the public sector [2];

\author{
Maltsev E.P. \\ Department of Civil-Legal and Economic Disciplines \\ Voronezh Institute of the Ministry of Internal Affairs of \\ Russia \\ Voronezh, Russia \\ e-mail: Madm86@mail.ru
}

Fomenko T.N

Department of Administration of Law Enforcement Agencies Voronezh Institute of the Ministry of Internal Affairs of Russia

Voronezh, Russia

fom.tan87@mail.ru

- the change and modification of the methods and methods for committing unlawful economic actions in the public sector.

In law enforcement practice there are a number of problems in distinguishing between the concepts of integrated and commission expertise in the budget sphere, in the interpretation of the concepts of "complex" and commission expertise. As the analysis of judicial practice has shown, both comprehensive and commission examination can be assigned on the same issue, a complex examination can be entrusted to one person, which contradicts existing approaches developed at the legislative and methodological levels

The results of the analysis allow stating that, when comparing the criteria; ten similarities and nine differences between the comprehensive and commission examination of illegal economic actions in the public sector were revealed.

The similarity criteria include the following: tasks solved by conducting a comprehensive or commission examination in the public sector; sources of information; purpose of the study; object of study; period of carrying out; examination planning; performers; principles used; leaders of an expert group; appointment of expertise. Criteria of distinction comprises the use of special knowledge; study limits; attitude to the evidence base of illegal actions; rights and obligations of experts; composition of an expert group; the need for expertise; order of participation of the expert; procedure for the production of expertise; use of expert procedures and methods.

Based on the proposed comparative analysis of commission and complex examinations on illegal economic actions in the budget sphere, we consider it possible to develop algorithms for conducting complex and commission examinations on illegal economic actions in the budget sphere.

The algorithm for conducting commission examinations on illegal economic actions in the public sector includes several stages of the examination: 
- preparation of an application from an authorized body (person), execution of a decision on conducting or on refusal to conduct a commission examination;

- appointment of a group of experts (at least 2 people) of one or various expert institutions, appointment of a leading expert institution and an expert organizer;

- familiarization of experts with the rights and obligations posed by questions, tasks, case materials;

- preparation of a schedule and program, selection of contractual, accounting, regulatory, planning and other information [3].

The next stage of commission examination is held in the format of a separate full-scale study conducted by each expert. In view of the fact that there must be at least 2 experts, we respectively designated each expert in the algorithm as expert 1, expert 2, etc. Throughout the entire period of the study, the leading expert organizes the work, solves the questions that arise in the process, ensures the safety of the research objects, and controls the timing of the work. Based on the comparison, comparison of objects of research in the dynamics of their behavior, experts prepare conclusions, and the leading expert then formulates a general integrated conclusion based on these conclusions, draws up measures to prevent violations of budgetary discipline.

It should be noted that in case of disagreement of one of the experts, a separate conclusion is given by each disagreeing with the opinion of other experts.

The algorithm for conducting comprehensive examinations on illegal economic actions in the budget sphere includes several stages of conducting an examination similar to the stages of conducting a commission examination, including the preparation of a schedule, selection of contractual, accounting, regulatory, planned and other information. It should be noted that a comprehensive examination is carried out by several experts of various specialties or narrow specializations (profiles). In the figure, experts of various specialties are designated as an expert of the 1st specialty, an expert of the 2nd specialty, etc. Experts examine objects related to their competence and formulate intermediate conclusions. The leading expert, based on the generated intermediate conclusions obtained as a result of synthesized application of the knowledge of experts of various specialties, formulates a general conclusion. Further, measures are taken to prevent violations of budgetary discipline. In case of disagreement, an expert who does not agree with the conclusions of other experts, signs only their research part.

To achieve optimal organization and increase the efficiency of the expert accountant during commission and complex examinations on illegal economic actions in the budget sphere, in order to prevent misuse of budget funds, there is a need to develop a methodology for organizing the work of an expert on commission and complex examinations on illegal economic actions in the public sector [4]. Considering the results of our research and the developed algorithms for conducting complex and commission examinations, the analysis of similarities and differences in conducting, the study of scientific literature and expert practice, we believe that this technique should include the following sections:

- which will include the following sections:

- purpose of the methodology;

- tasks of the methodology;

- information base;

- performers and terms of use;

- organizational stage;

- Expert Advisor Algorithm;

- conclusion based on the results of commission or complex expertise.

\section{The Methodology of THE EXPERT ACCOUNTANT IN CONDUCTING COMPLEX AND COMMISSION EXAMINATIONS OF ILLEGAL ECONOMIC ACTIONS IN THE PUBLIC SECTOR}

1. The purpose of the methodology:

1.1. Methodological support for the work of an expert accountant in conducting complex and commission examinations on illegal economic actions in the public sector with the aim of preventing the misuse of budget funds.

2. The tasks of the expert accountant's methodology in conducting comprehensive and commission examinations on illegal economic activities in the public sector in order to prevent misuse of budget funds:

2.1. Development of proposals for complex and commission examinations;

2.2. Determination of the amount of damage and the circle of persons involved in the commission of an unlawful economic action in the public sector;

2.3. Determination of the composition of the expert group;

2.4. Reducing the period for commission and comprehensive examinations;

\subsection{Improving the quality of examinations}

3. The information base of the work of an expert accountant during a comprehensive and commission examination of illegal economic activities in the public sector:

3.1. Conclusion of an expert accountant, reference and regulatory materials (instructions, orders, decisions), results of investigative actions (experiments, interrogations, etc.), documents of accounting (financial) statements, results of other examinations.

\subsection{Primary documents, accounting registers.}

3.3. Accounting documents, accounting accounts that reflect the features of the organization of accounting in the public sector.

4. Contractors and terms of use of the work methodology of an expert accountant during complex and commission examinations of illegal economic actions in the budget sphere: 
4.1. Complex and commission examinations are entrusted to the group of experts who are qualified to formulate professional judgments on the organization of work when conducting complex and commission examinations on illegal economic activities in the budget sphere.

4.2. The timing of the examination depends on the following factors:

- parameters of the investigated object and the studied period, which should cover the examination;

- the amount of initial information, its quality and type (electronic or paper) of the documents and materials submitted for the study;

- number of violations and inconsistencies, degree of repeatability;

- the nature of the committed illegal act or the number of episodes of unlawful behavior;

- the degree of possible coordination of the actions of experts during a comprehensive or commission examination;

- timeliness of the provision of information;

- competence and experience of experts, lack or presence of negligence or superficiality when conducting research;

- the state of accounting of the studied economic entity of the public sector at the time of the examination;

- the absence or presence of gnoseological errors that arise in the study of the essence, properties, signs of the object (violation of the procedural regime and the examination procedure, going beyond the competence, substantiating conclusions not with the results, but with the case materials, contacting with interested parties, accepting materials from unauthorized persons and etc.), as well as logical, factual errors (for example, omnimony - mixing or substitution of concepts), activity (violation of the research sequence)

- identification of additional circumstances during the accounting examination.

5. The organizational stage of the work of an expert accountant in conducting comprehensive and commission examinations on illegal economic actions in the budget sphere for the prevention and prevention of misuse of budget resources:

5.1. The determination of expert procedures used when using the examination methodology is carried out in relation to the specifics of conducting complex and commission examinations on illegal economic actions in the budget sphere, taking into account the prevention of illegal actions;

5.2. Identification and determination of the procedure for using documentary methods of accounting expertise in conducting complex and commission examinations of illegal economic activities in the public sector;

5.3. The objects of research during the commission examination are determined depending on the objects of accounting and off-site objects that have been subjected to unlawful influence;

5.4. The objects of research during a comprehensive examination are determined depending on the specialties (specializations) of the experts, the type of examination and objects that have been subjected to unlawful influence;

5.5. Expert procedures for conducting commission expertise on illegal economic activities in the public sector;

5.6. Organization of the work of an expert accountant during the commission examination of illegal economic actions in the public sector. When using the methodology during the commission examination, the following expert accounting expert procedures are applied:

- organizational - to conduct an examination, draw up organizational and administrative documentation, determine the objects of research, select a research methodology, determine the location of the examination, etc.;

- regulatory - a set of actions related to the study of the functioning of the object of examination in accordance with applicable law and regulations

- analytical - dismemberment of the object of expert accounting research into the constituent elements and study them using special methods

- settlement and computing - an individual system of calculations used in the study of the reliability of quantitative and cost indicators of perfect facts of economic life;

- logical - the use of logical interconnection techniques when conducting expert research between the event of a specific illegal act and officials who had the opportunity to commit it; between inconsistencies in the accounting process and facts of illegal activity, etc.

5.7. When using the methodology during a comprehensive examination, the expert procedures of accounting expertise and expert methods are applied that correspond to the type of examination being carried out;

5.8. The stage of planning the work methodology of an expert accountant during complex and commission examinations on illegal economic actions in the budget sphere, taking into account the prevention of misuse of budget resources, involves the following actions:

- determination of the scope of work with the preparation of a schedule and program;

- the time of the work depends on the timing of the appointment of the examination and the conduct of a comprehensive or commission examination, is included in the plan for its implementation;

- determination of the duration of use of the considered methodology of a comprehensive or commission examination; 
- selection of contractual, accounting, regulatory, planning, and other information depending on the type of examination being conducted.

6. The algorithm of the expert accountant during a comprehensive and commission examination of illegal economic activities in the public sector:

\subsection{Generalization and analysis of information.}

6.2. Determination of the presence or absence of an unlawful action on the basis of the information provided.

6.3. Determining the list of persons involved in the commission of an unlawful economic action.

6.4. Identification of the type of activity associated with unlawful economic action.

6.5. Making decisions based on the results of a commission or comprehensive examination in accordance with applicable law and formulating proposals;

6.6. Paperwork with ready-made expert decisions and a list of measures to prevent illegal economic activities in the field of budget relations.

6.7. Bringing the proposed measures to the authorized body when providing an expert opinion.

6.8. Identification of the most problematic areas in the activity of an economic entity in the absence of illegal actions in the public sector.

7. Conclusion based on the results of a comprehensive or commission examination on illegal economic actions in the budget sphere:

7.1. The conclusion on the results of a comprehensive or commission examination in the budget sphere and making proposals is compiled in the form and using the methods developed in the system of the Ministry of Internal Affairs of Russia, in accordance with the documents of the information base.

7.2. The methodology of the expert accountant in conducting a comprehensive and commission examination of illegal economic actions in the budget sphere is applied at all stages of the accounting examination. Conclusions are formed and reflected in the conclusion at the stage of systematization and fixing the results of a comprehensive examination.

\section{CONCLUSION}

The proposed methodology was tested during complex and commission examinations on illegal economic actions in the public sphere by experts of expert-forensics department of the Main Directorate of the Ministry of Internal Affairs of Russia in Voronezh region.

Thus, in this work, the methodology for the work of an expert accountant in carrying out complex and commission examinations on illegal economic actions in the field of budgetary relations has been developed. This methodology is based on comparative analysis of complex and commission examinations of illegal economic actions in the public sector and on nineteen criteria. The algorithms for conducting complex and commission examinations on illegal economic actions with budgetary resources allow optimizing and managing the work of expert accountants in the process of working in complex and commission examinations. The developed author's methodology makes it possible to efficiently organize an expert accountant in the commission of experts of both his own and related specialties, determines the procedure for the expert accountant to investigate the misuse of budget funds at all stages of a complex or commission examination.

\section{References}

[1] L.V. Kashirskaya, Methodology in Organising Accounting Expertise in State-funded Organisations (Doct. Dissertation Thesis). Moscow, 2013

[2] I.E. Strygina, "Accounting Expertise in Court under Condition of Computer Systems Usage", Law and Ed., vol. 3, pp. 157-165, 2013.

[3] S.A. Zvyagin, E.P. Maltsev, "Managing Accounting Expertise in Modern Conditions", Proc. of Voronezh State Univer., Ser. Econ. and Manag., vol. 4, pp. 24-28, 2017.

[4] Zh.A. Kevorkova, A.A. Savin, Accounting Expertise in Court, Textbook. Moscow, 2005 